ably reflecting GABA in glial cells. To obtain extracellular GABA, which is at least partially dependent on neuronal activity, GABA-ergic neurons have to be stimulated. To study the dopaminergic modulation of extracellular GABA levels in the substantia nigra reticulata, dopaminergic drugs were infused into the substantia nigra reticulata. $A D_{2}$ agonist did not affect GABA levels, while a D1 agonist induced an increase in extracellular GABA levels, which persisted in the presence of tetrodotoxin, a drug that abolishes the nerve impulse-flow. Thus, the $D_{1}$ agonist affected GABA levels independent of neuronal activity. Further study is needed to elucidate the underlying mechanism.

\section{Results have also been published in the following papers:}

- Timmerman W, Westerink BHC, De Vries JB, Tepper PG, Horn AS. Microdialysis and striatal dopamine release: stereoselective actions of the enantiomers of $\mathrm{N}-0437$. Eur / Pharmacol 1989;162:143-50.

- Timmerman W, Dubocovich ML, Westerink BHC, De Vries JB, Tepper PG, Horn AS. The enantiomers of the dopamine ago- nist N-0437: in vivo and in vitro effects on the release of striatal dopamine. Eur J Pharmacol 1989;166:1-11.

- Timmerman W, Rusk IN, Horn AS, Cooper SJ. The effects of the enantiomers of the dopamine agonist $\mathrm{N}-0437$ on food consumption and yawning behaviour in rats. Eur I Pharmacol 1989; 174:107-14.

- Timmerman W, Tepper PG, Bohus BGJ, Horn AS. The potential antipsychotic activity of the dopaminergic partial agonist (+)N-0437. Eur I Pharmacol 1990;181:253-60.

- Timmerman W, De Vries IB, Westerink BHC. Effects of D-2 agonists on the release of dopamine. Localization of the mechanism of action. Naunyn Schmiedebergs Arch Pharmacol 1990;342:650-4.

- Timmerman W, Tepper PG, Dijkstra D, Grol Cl, Westerink BHC, Horn AS. Enantiomers of monohydroxy-2-aminotetralin derivatives and their activity at dopamine autoreceptors as studied by brain dialysis. Eur / Pharmacol 1991;199:145-51.

- Timmerman W, Westerink BHC. Importance of the calcium content infused during microdialysis for the effects induced by $\mathrm{D}-2$ agonists on the release of dopamine in the striatum of the rat. Neurosci Lett 1991;131:93-6.

- Timmerman W, Zwaveling I, Westerink BHC. Dopaminergic modulation of the GABA release in the substantia nigra reticulata. In: Rollema H, Westerink BHC, Drijfhout WI, eds. Monitoring molecules in neuroscience. Groningen: University of Groningen, 1991:105-7.

- Timmerman W, Zwaveling I Westerink BHC. Characterization of extracellular CABA in the substantia nigra reticulata by means of brain microdialysis. Naunyn Schmiedebergs Arch Pharmacol 1991;345:661-5.

\title{
The biotechnological production of podophyllotoxin and related cytotoxic lignans by plant cell cultures
}

\author{
- W. Van Uden
}

The abstract of Dr. W. Van Uden's doctoral thesis, published in Pharm World Sci 1993;15(1):41-3, unfortunately contained several printing errors. The address of Dr. Van Uden was incorrect; it should have read: Department of Pharmacognosy, University Centre for Pharmacy, University of Groningen, Ant. Deusinglaan 2, 9713 AW Groningen, the Netherlands. The status of Dr. N. Pras was omitted; he was a referee for this graduation. Finally, the keyword 'Celle, cultured' should have read Cells, cultured. 